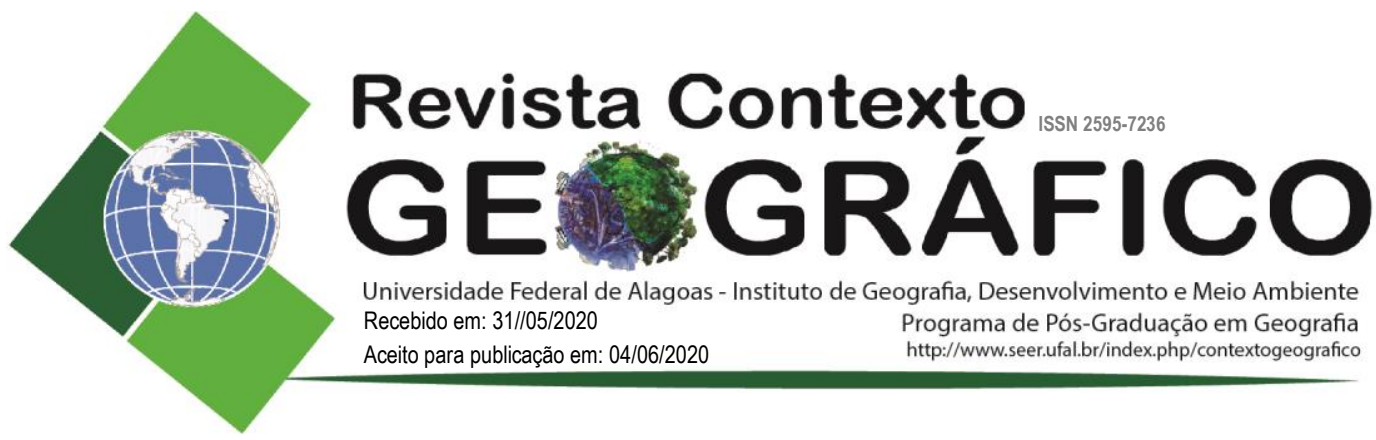

\title{
ANÁLISE DA DISTRIBUIÇÃO ESPACIAL DOS SÍTIOS ARQUEOLÓGICOS DA BACIA DO RIO CARNAÚBA-RN A PARTIR DA CLASSIFICAÇÃO DA MORFOLOGIA DOS SUPORTES ROCHOSOS E DAS UNIDADES GEOMORFOLÓGICAS
}

\author{
Beatriz Araujo Medeiros \\ Graduação em Arqueologia, Universidade Federal de Pernambuco, PE, Brasil \\ bamedeiross@gmail.com
}

Bruno de Azevedo Cavalcanti Tavares

Professor do Departamento de Arqueologia / Universidade Federal de Pernambuco, PE, Brasil

bruno.tavares@ufpe.br

Demétrio da Silva Mützenberg

Professor do Departamento de Arqueologia / Universidade Federal de Pernambuco, PE, Brasil demetrio.mutzenberg@ufpe.br

\begin{abstract}
RESUMO - Esta pesquisa teve como objetivo realizar o mapeamento geomorfológico para a área do vale do rio Carnaúba, Rio Grande do Norte, utilizando-se de parâmetros comparativos entre a distribuição geográfica dos sítios arqueológicos ao longo da bacia e suas classes de vestígios, a partir de bases metodológicas da Geoarqueologia e Arqueologia Espacial, a fim de verificar se é possível estabelecer uma relação entre estes aspectos. Como resultado do mapeamento, foram classificadas e descritas 10 unidades geomorfológicas distintas e os sítios pré-históricos mapeados na área de estudo foram classificados em: (i) Abrigo; (ii) Céu aberto; e (iii) Paredão. Foi possível observar um padrão entre os níveis hipsométricos e a proximidade às margens do rio principal e seus principais tributários como os aspectos mais evidentes para a escolha das diferentes práticas de assentamento.
\end{abstract}

Palavras-chave: Geoarqueologia; Arqueologia Espacial; Seridó; Vale do rio Carnaúba.

\section{SPATIAL DISTRIBUTION ANALYSIS OF THE ARCHAEOLOGICAL SITES OF CARNAUBA'S RIVER BASIN FROM THE MORPHOLOGY CLASSIFICATION OF THE ROCKY SUPPORT AND GEOMORPHOLOGICAL UNITS}

\begin{abstract}
This research's objective was to perform the geomorphological mapping of the Carnaúba River's basin, Rio Grande do Norte state. Brazil, utilizing comparative parameters between the geographical distribution of the archaeological sites along the basin's area and its record types, from methodological bases of Geoarchaeology and Spatial Archaeology, with the intent of verifying the possibility to stablish a relation between those aspects. As a result of the mapping, 10 distinct geomorphological units were classified and described, and the prehistoric sites mapped in the research's area were classified as: (i) Rock Shelter; (ii) Open Air; and (iii) Rock Wall/Vertical Scarpment; It was possible to perceive a pattern between the hypsometric levels and the proximity to the main river's margin and its major tributaries as prominent aspects in selecting one of the many different settlement practices.
\end{abstract}

Keywords: Geoarchaeology; Spatial Archaeology; Seridó; Carnaúba river. 
MEDEIROS, B. A.; TAVARES, B. A. C.; MÜTZENBERG
ANÁLISE DA DISTRIBUIÇÃO ESPACIAL DOS SÍTIOS ARQUEOLÓGICOS DA BACIA

DO RIO CARNAÚBA-RN A PARTIR DA CLASSIFICACÃO DA MORFOLOGIA DOS

SUPORTES ROCHOSOS E DAS UNIDADES GEOMORFOLÓGICAS

\section{INTRODUÇÃO}

Nesta pesquisa o ecossistema é entendido como uma comunidade de organismos em uma determinada área interagindo com o ambiente físico (ODUM 1971:8 apud BUTZER, 1982). Tal conceito, aplicado por Butzer (1982) em populações humanas, acentua-se uma das necessidades primárias da Geoarqueologia: entender a influência mútua entre meio ambiente, ser humano e suas práticas culturais na área de estudo. Sendo os componentes essenciais do ambiente não cultural: distância ou espaço, topografia ou formas de relevo, e recursos bióticos, minerais e atmosféricos. Nesse sentido, a pesquisa foi direcionada para a área arqueológica do Seridó baseada na quantidade expressiva de sítios arqueológicos encontrados e registrados na área, a relevância para as pesquisas de ocupação humana no Nordeste e compreensão do paleoclima e evolução da paisagem, além da produção científica nos últimos 100 anos, iniciada por José de Azevêdo Dantas no início do século XX (DANTAS, 1994), e exponencialmente desenvolvida por diversos autores (MARTIN, 1989; 1994; 1996; 2003; VIDAL, 1995; SILVA, 2003; VALLE, 2003; LEITE, 2004; MUTZENBERG et al., 2005; NOGUEIRA e MAFRA, 2014; NOGUEIRA, 2016; SOLARI et al., 2016; NOGUEIRA, 2017). A área de pesquisa foi delimitada mais especificamente para a bacia do rio Carnaúba. Seguindo isto, foram observados dados de contagem e caracterização dos sítios arqueológicos, possibilitando o delinear de uma relação entre estes e a atual paisagem física no vale do Rio Carnaúba, notando-se padrões claros de assentamento e classes vestigiais (MUTZENBERG, 2007; CHAGAS JÚNIOR, 2017).

O vale do rio Carnaúba está situado na Mesorregião Central Potiguar, na Microrregião do Seridó Oriental e inserido nos municípios de Carnaúba dos Dantas (RN) e Acari (RN). A bacia é caracterizada por armazenar significante volume de água em seu lençol freático, que é um dos últimos a secar em relação às regiões circunvizinhas, o que a torna privilegiada para ocupações humanas de variadas temporalidades, conferindo uma gama diversa de registros pré-históricos (MUTZENBERG, 2007), questão esta que, aliada aos argumentos apresentados anteriormente, justificam a escolha da área para a análise abordada (Figura 1).

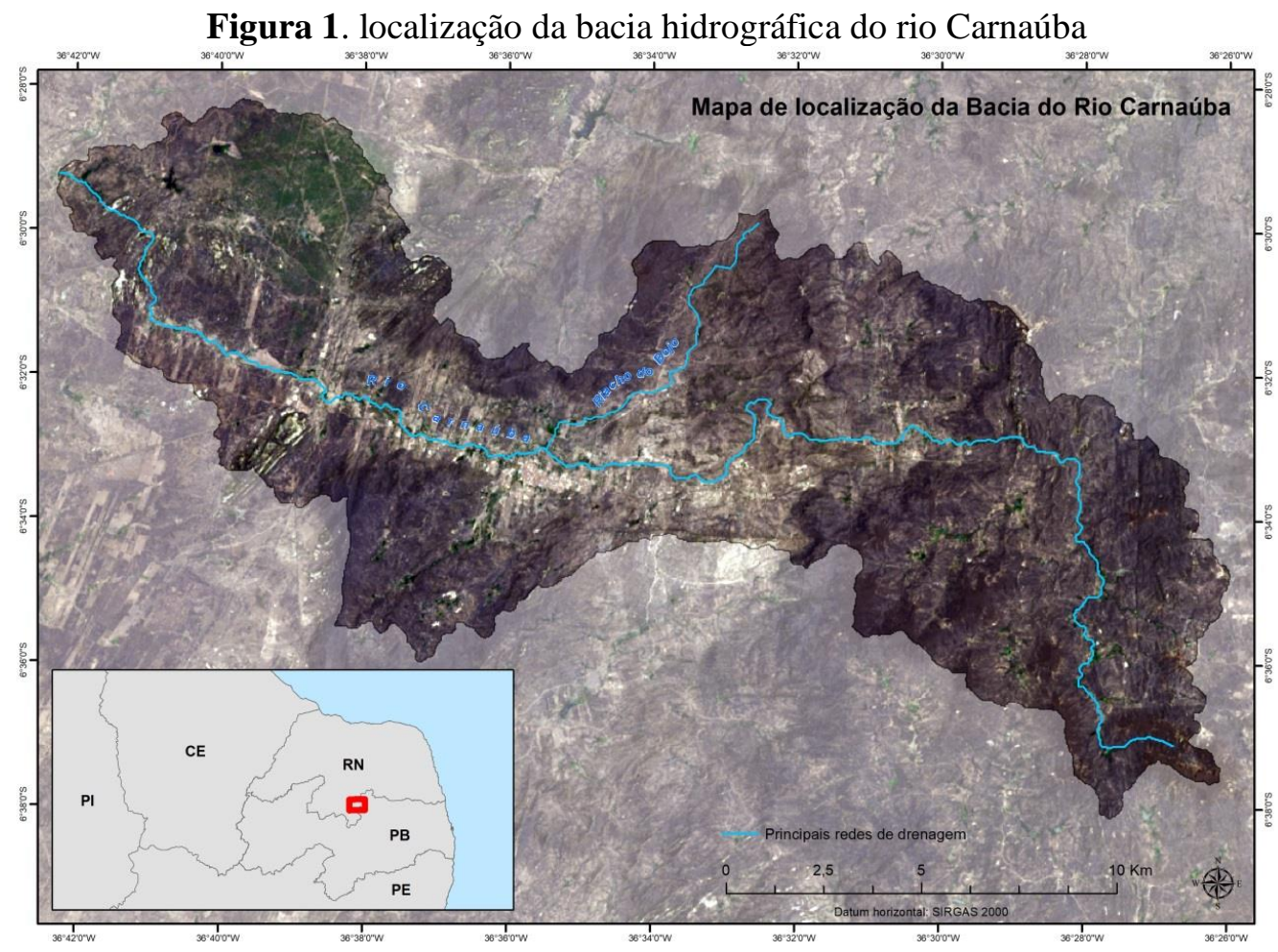


MEDEIROS, B. A.; TAVARES, B. A. C.; MÜTZENBERG
ANÁLISE DA DISTRIBUIÇÃO ESPACIAL DOS SÍTIOS ARQUEOLÓGICOS DA BACIA

DO RIO CARNAÚBA-RN A PARTIR DA CLASSIFICAÇÃ̃O DA MORFOLOGIA DOS

SUPORTES ROCHOSOS E DAS UNIDADES GEOMORFOLÓGICAS

Org. Autores (2020)

Dessa forma, a pesquisa posiciona-se como uma possível fonte de consulta no que diz respeito ao mapeamento geomorfológico da região, até então não realizado, e o mapeamento direto da correlação entre paisagem e tipos morfológicos de sítios arqueológicos. Sendo, então, uma contribuição passível de referência para aplicação no desenvolvimento de futuros estudos na bacia ou em outras regiões, além do uso como suporte para o entendimento de outras problemáticas.

\section{ANTECEDENTES ARQUEOLÓGICOS E CARACTERIZAÇÃO DA ÁREA}

A área arqueológica do Seridó é uma das mais estudadas pelos pesquisadores em Arqueologia do Nordeste brasileiro (MARTIN, 2013), e, provavelmente, a mais expressiva em termos arqueológicos em toda região do Rio Grande do Norte. Tornou-se foco de pesquisas desde a presença de cronistas e naturalistas, mas foi especialmente estudada no início do século XX pelo autodidata local José de Azevêdo Dantas, que abordava temas da Arqueologia, História, Geografia, Geneaologia, Meteorologia, e diversas áreas afins (MACEDO, 2009).

José de Azevêdo Dantas iniciou suas pesquisas na região do Xiquexique, local onde nasceu, e visitou os locais por ele denominados Rochedo Pinturas ou Talhado das Pinturas, Rochedo do Xiquexique, Rochedo da Serra do Xiquexique e Rochedo do Pau d'Arco, hoje correspondentes aos sítios arqueológicos Xique-xique I, Xique-xique II, Abrigo do Morcego e Furna do Pau d'Arco, respectivamente, todos com pinturas da Tradição Nordeste, Subtradição Seridó e Estilo Carnaúba (MARTIN, 2003; MACEDO, 2009). Prosseguiu suas pesquisas fazendo registros das inscrições rupestres no Riacho do Bojo e Riacho do Olho d'Água, afluentes do rio Carnaúba, além na área do entorno da bacia, nos municípios de Acari, Parelhas e Picuí. Suas observações e registros resultaram na formulação do texto "Indícios de uma Civilização Antiqüíssima" em 1925, sendo publicado postumamente na década de 1990 (DANTAS, 1994).

Entre 1966 e 1985, a região do Seridó passou a ser percorrida por instituições como o Instituto do Patrimônio Histórico e Artístico Nacional (IPHAN) e o Instituto de Antropologia da Universidade Federal do Rio Grande do Norte com a finalidade de realizar registros escritos e fotográficos de sítios, grafismos e vestígios, e mapear a distribuição dos sítios, formalizando em fichas cadastrais. De acordo com pesquisas de Macedo (2009), naquele momento foram registrados os sítios Xiquexique I e II (em maio/1978), Pedra do Alexandre, Pote, Serrote do Gavião, Furna dos Caboclos, Casa Santa (25/08/1977), Volta do Rio (06/1978) e Criminoso (06/1978) em Carnaúba dos Dantas.

A professora Gabriela Martin, encabeçando o Núcleo de Estudos Arqueológicos (NEA) da Universidade Federal de Pernambuco, coordenou algumas das mais expressivas pesquisas e interpretações a respeito das ocupações pré-históricas no Nordeste brasileiro, em especial no Seridó. Com a referência dos estudos realizados por Guidon (1975) na Serra da Capivara, Piauí, para a metodologia na atribuição da Tradição Nordeste na região, Martin (1982) definiu o Estilo Seridó, classificação inicial para descrever estilos semelhantes de grafismos rupestres, estes de tamanho reduzido, de cores vermelha, amarela, branca e preta, dominância das figuras antropomorfas, utilização recorrente de elementos materiais para identificar as representações gráficas, uso de temáticas de representações sexuais, agressão, rituais cerimoniais em torno de árvore e antropomorfos costa a costa, que posteriormente tornou-se a Subtradição Seridó (MARTIN, 1989).

Após a cronologia dada aos registros da Subtradição Seridó, foram identificados padrões classificados como Estilo Carnaúba, que se caracterizam por cabeças em perfil ou, como popularmente conhecidos, cabeças de castanha-de-caju, e cenas cerimoniais, e o que se 
MEDEIROS, B. A.; TAVARES, B. A. C.; MÜTZENBERG
ANÁLISE DA DISTRIBUIÇÃO ESPACIAL DOS SÍTIOS ARQUEOLÓGICOS DA BACIA DO RIO CARNAÚBA-RN A PARTIR DA CLASSIFICAĈ̃̃O DA MORFOLOGIA DOS SUPORTES ROCHOSOS E DAS UNIDADES GEOMORFOLÓGICAS

considera a fase final da Subtradição Seridó, caracterizada pelo geometrismo e maior detalhamento de pinturas e acessórios em antropomorfos (MARTIN, 2003). Além da Tradição Nordeste, ainda se encontram grafismos das tradições Agreste e Itaquatiara, esta última sendo principalmente formada por grafismos relacionados à suportes próximos à cursos d'água. Ainda no início dos anos 1990, o NEA deu início às primeiras escavações no sítio Pedra do Alexandre, o qual "forneceu as datações mais antigas do Nordeste para um abrigo-cemitério, um enterramento secundário de criança de quatro a cinco anos foi datado em 9400 anos BP" (MARTIN, 1996), e onde também foram encontrados artefatos líticos, fogueiras, enterramentos primários e secundários, vestígios de fauna e fragmentos cerâmicos.

Atualmente, a área em questão possui mais de 90 sítios cadastrados no IPHAN e uma história de ocupação humana que vai até a Transição Pleistoceno/Holoceno. Esse setor apresenta uma gama de sítios arqueológicos com diversos vestígios da cultura material do homem nordestino préhistórico. São vestígios como os grafismos rupestres, indústrias líticas em sítios à céu aberto (SALDANHA, 2014), estruturas de combustão complexas (NOGUEIRA, 2017) e evidências de um passado de ocupação em condições ambientais distintas do semiárido contemporâneo, onde a presença de algumas feições geomorfológicas dão indicativo e sugerem que a dinâmica ambiental trazia condições mais favoráveis para uma intensa ocupação na área (MUTZENBERG, 2007).

A bacia do rio Carnaúba, a área de estudo da presente pesquisa, de caráter intermitente e dendrítico, possui $48 \mathrm{~km}$ de extensão, está geomorfologicamente inserida entre os domínios do Planalto da Borborema e Depressão Sertaneja e geologicamente no domínio geológico da Faixa Seridó, seccionando as unidades litoestratigráficas de idade neoproterozóicas da Suíte de Médio a Alto Potássio Itaporanga e do Grupo Seridó, que é subdividido em quatro formações: Formação Seridó, constituída de micaxistos feldspáticos ou aluminosos, biotita-xisto, metarritmitos e clorita-sericita xisto; Formação Equador, constituída de muscovita quartzitos e metaconglomerados (CPRM, 2010). A região corta perpendicularmente a Zona de Cisalhamento Transcorrente Dextral Carnaúba dos Dantas e a Falha Transcorrente Sinistral em orientação EW (MÜTZENBERG, 2007) e abrange, ainda, a Suíte Intrusiva Dona Inês e a Formação Serra dos Martins, de cronologia cenozóica e que forma relevos tabuliformes nas porções mais elevadas do vale constituídas por arenitos médios a conglomeráticos, arenitos argilosos e crostas lateríticas com seixos de quartzo (CHAGAS JÚNIOR, 2017). O rio Carnaúba é afluente do rio Acauã, que por sua vez é afluente do rio Seridó, pertencente à rede da bacia hidrográfica Piranhas-Açu.

O clima atual é semiárido, quente e seco. A precipitação anual é de, em média, 447,8 mm, sofrendo com um processo intenso de desertificação causado por condicionantes naturais e antropogênicos atrelados ao uso e ocupação da terra, como, por exemplo, o desmatamento para produção cerâmica, bem como a extração mineral (COSTA et al., 2009). Em contraponto, no que diz respeito às condições pretéritas, o acúmulo de sedimentos alúvio-coluvionares, terraços e leques fluviais demonstram que as condições paleoambientais apresentavam períodos mais úmidos, de maior dinâmica e fluxo fluvial, com largas várzeas úmidas dos cursos subterminais (MÜTZENBERG et al., 2005; MÜTZENBERG, 2007; CHAGAS JÚNIOR, 2017). Essas condições respaldam, na perspectiva geoarqueológica, o rio Carnaúba como, além de culturalmente relevante e provedor de recursos, uma importante via de comunicação entre os grupos humanos.

Ao que se refere à pedologia, estudos descreveram dois tipos de solos presentes na bacia do rio Carnaúba: Neossolo Litólico Eutrófico, Luvissolo Crômico Órtico e o Neossolo Flúvico, este último correspondendo os setores de fundo do vale do rio Carnaúba e amplamente utilizado para as práticas agrícolas e as indústrias de cerâmica. $\mathrm{O}$ primeiro, localizado das cabeceiras até o médio curso do rio em áreas de relevo ondulado, forte ondulado e montanhoso, possui pouca profundidade e ausência do horizonte $\mathrm{B}$, já o segundo, se apresenta mormente no baixo curso 
MEDEIROS, B. A.; TAVARES, B. A. C.; MÜTZENBERG
ANÁLISE DA DISTRIBUIÇÃO ESPACIAL DOS SÍTIOS ARQUEOLÓGICOS DA BACIA

DO RIO CARNAÚBA-RN A PARTIR DA CLASSIFICAC̃̃O DA MORFOLOGIA DOS SUPORTES ROCHOSOS E DAS UNIDADES GEOMORFOLÓGICAS

bacia, estando presente em relevo suave ondulado, com horizontes bem definidos e distintos, apresenta textura cascalhosa e pouca profundidade (Santos et al., 2018).

Analisar e correlacionar as variáveis ambientais permite, por exemplo, a observação de determinados padrões, como as diferentes produções de grafismos rupestres a depender do suporte rochoso. Portanto, diante de todo esse arranjo ambiental, cultural e social, o trabalho propõe uma abordagem de enfoque geomorfológico para fornecer novas contribuições à intepretação da disposição espacial dos sítios arqueológicos na bacia do rio Carnaúba, e como esse elemento da paisagem pode ter sido fundamental na escolha de locais estratégicos para assentamento dos povos originários do Nordeste do Brasil.

\section{MÉTODOS E TÉCNICAS}

Para a realização do trabalho foi utilizada a técnica de mapeamento geomorfológico a partir das normas de Demek e Embleton (1978) e a do manual técnico de Geomorfologia do IBGE (NUNES et al., 2009). As metodologias utilizadas favorecem o uso de quatro elementos para o entendimento das peculiaridades geomórficas da área: morfometria, morfologia, gênese e cronologia relativa. O detalhamento do mapeamento geomorfológico permite uma visualização individual das morfologias denudacionais e seus respectivos condicionantes morfoestruturais. Procura-se, no entanto elaborar uma representação que aponte em linhas gerais as subordinações entre a forma, suas dimensões, materiais formadores e processos vigentes e pretéritos. Os modelos numéricos foram extraídos a partir de imagens ALOS/PALSAR, com resolução de 12.5 metros. Neste trabalho, as informações utilizadas foram o modelo digital de elevação (MDE) e a distribuição de isoípsas extraídas do MDE em ambiente ArcGis, versão 10.3. O mapa geomorfológico foi confeccionado através da edição de vetores a partir das normas de classificação apresentada anteriormente. O sistema de coordenadas utilizado para elaboração dos mapas foi o SIRGAS 2000. Para a realização do mapeamento geomorfológico foram confeccionados os mapas base de declividade e hipsometria para auxiliar na delimitação das unidades (Figuras 2 e 3 ).

Figura 2. Hipsometria da bacia hidrográfica do rio Carnaúba

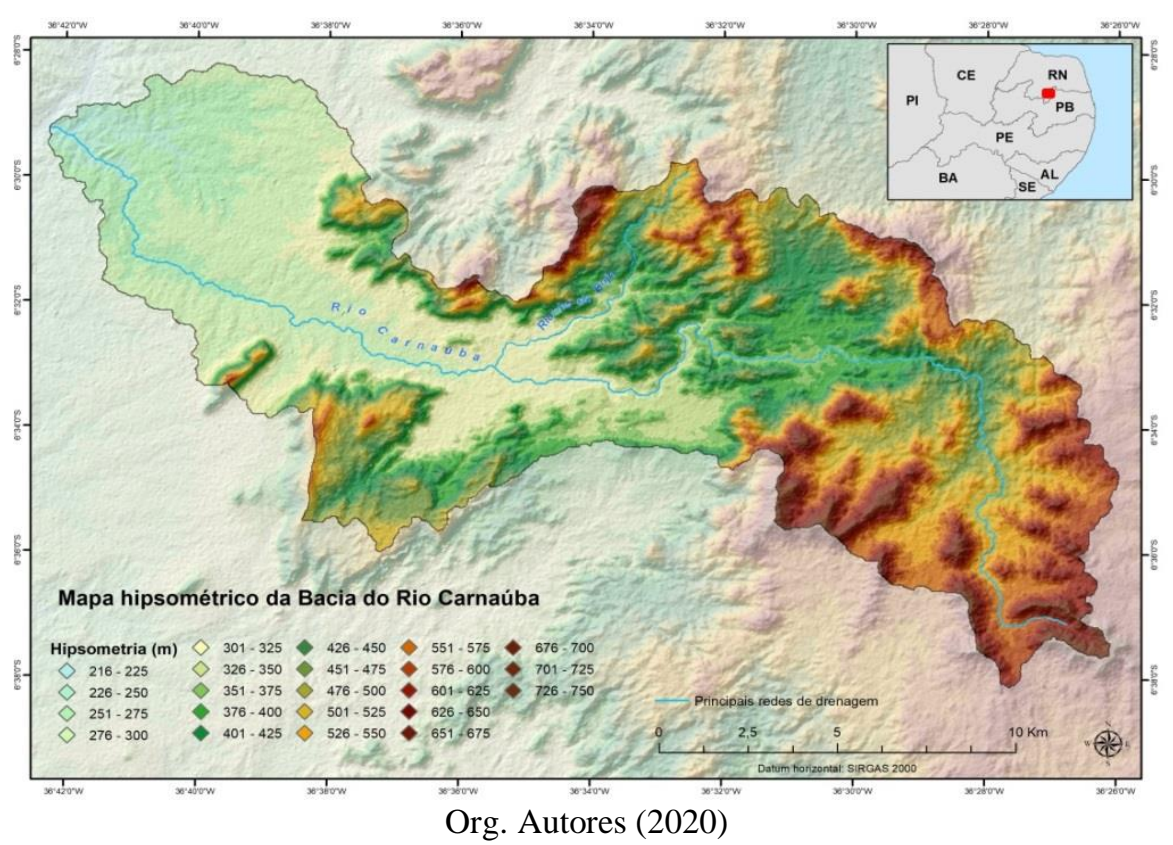


Figura 3. Declividade da bacia hidrográfica do rio Carnaúba

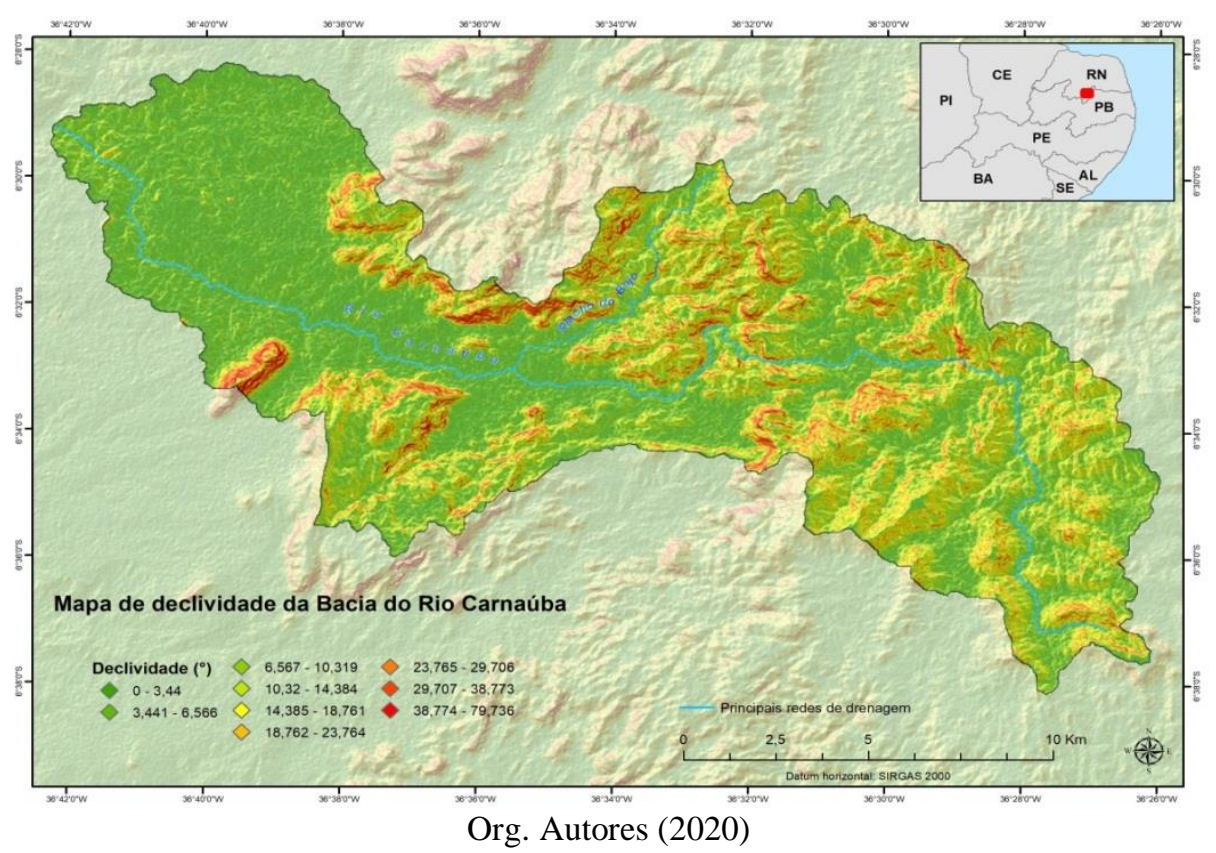

Aliado a isso, foram utilizados suportes teóricos da Geoarqueologia e Arqueologia Espacial, e técnicas práticas, denotadas por visitas de campo para observação, registro visual e de georreferenciamento (para correção das unidades geomorfológicas), além de referências bibliográficas sobre a formação paleoambiental, caracterização de sítios específicos, e contextualização ambiental da área de estudo e regiões circunvizinhas.

A análise da pesquisa foi desenvolvida com base na contagem e caracterização vestigial e geomorfológica em relação ao vale do Rio Carnaúba de 39 sítios arqueológicos, estes classificados em: (i) Abrigo; (ii) Céu aberto e (iii) Paredão, retirados da base de dados da Fundação Seridó (MARTIN, 2013). Os sítios em abrigo estão vinculados a ambientes essencialmente de encosta (baixa, média e alta vertente) onde controles litológicos e/ou estruturais, associados ao intemperismo físico e químico formam as cavidades, também denominadas de encostas negativas, esses setores protegidos ao longo da vertente são locais muitas vezes de escolha pelos grupos pré-históricos com a finalidade de ocupação. Os sítios à céu aberto são caracterizados por não apresentarem sob a proteção de um abrigo rochoso, estando muitas vezes associados aos ambientes de fundo de vale, como os terraços fluviais e os pedimentos, ou até mesmo vales fechados (Nogueira e Mafra, 2014). Os sítios caracterizados como paredão, correspondem aos ambientes onde os vestígios gráficos (pintura e/ou gravura) estão registrados nas rochas, estas sem estarem vinculadas a um abrigo rochoso, apenas o suporte vertical para os grafismos, esta feição está vinculada aos vales em gargalo dos riachos e principais tributários do rio Carnaúba. Por fim, a representação distributiva dos sítios arqueológicos em ambiente SIG (Sistema de Informações Geográficas). Para tal procuramos a partir dos dados geográficos elencados acima, trabalhar com a escala de 1:100.000 a fim de obter um registro geomorfológico de caráter detalhado, isso dentro do contexto da Bacia do rio Carnaúba.

\section{RESULTADOS E DISCUSSÕES}

O mapeamento geomorfológico da bacia do rio Carnaúba revelou uma série de compartimentos 
MEDEIROS, B. A.; TAVARES, B. A. C.; MÜTZENBERG
ANÁLISE DA DISTRIBUIÇÃO ESPACIAL DOS SÍTIOS ARQUEOLÓGICOS DA BACIA

DO RIO CARNAÚBA-RN A PARTIR DA CLASSIFICAČ̃O DA MORFOLOGIA DOS SUPORTES ROCHOSOS E DAS UNIDADES GEOMORFOLÓGICAS

de relevo ora vinculados a controles geológicos ora a controles de ordem climática (Figura 4).

Figura 4. Unidades geomorfológicas da Bacia do Rio Carnaúba. Destaque para a concentração de sítios em abrigos nos setores de encosta e os sítios em paredão no eixo de drenagem do tributário principal do Carnaúba.

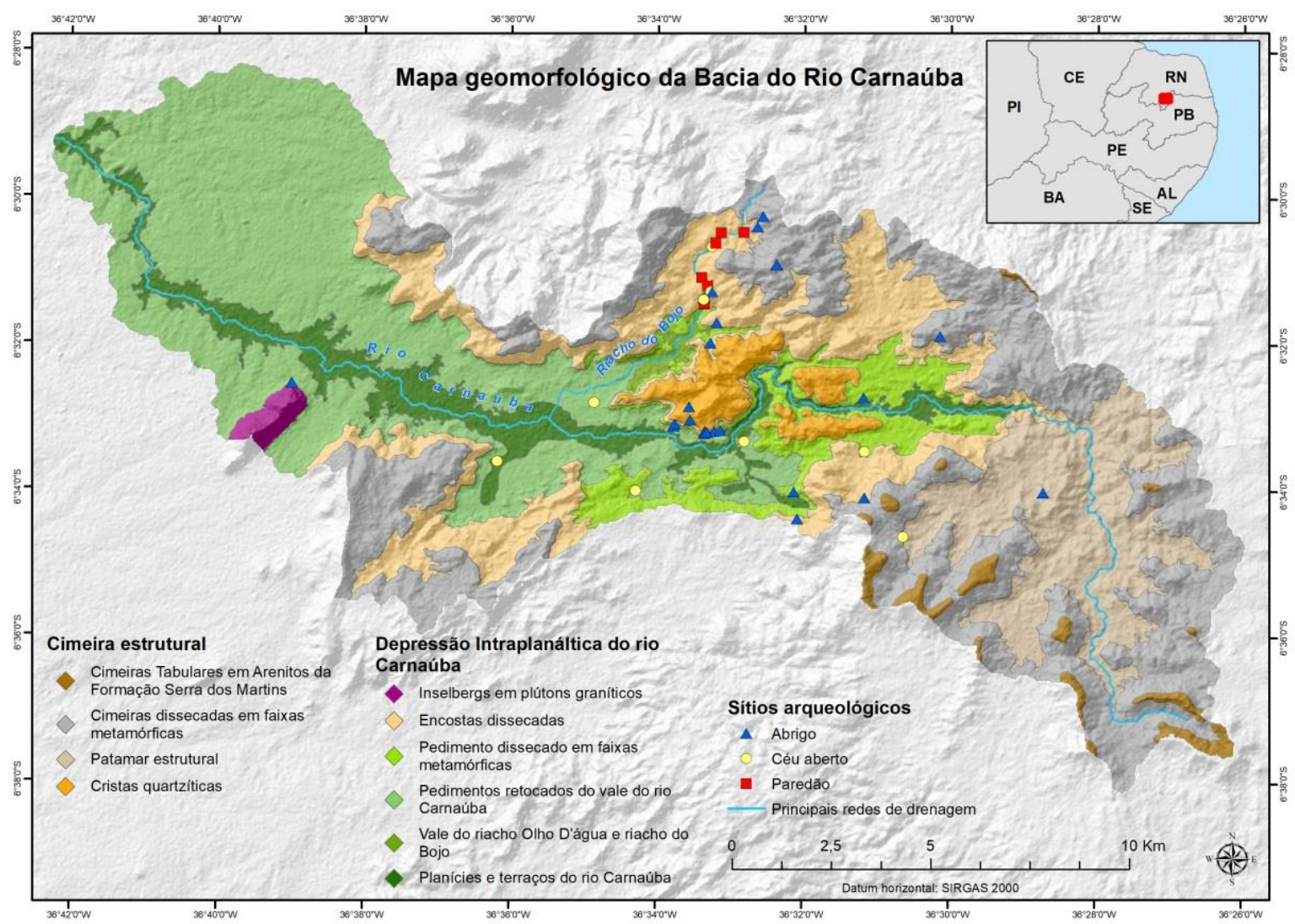

Org. Autores (2020)

A bacia do rio Carnaúba foi classificada em 10 unidades geomorfológicas, onde estas estão distribuídas em dois grandes compartimentos morfoestruturais, a Cimeira estrutural (onde se localizam as Cimeiras Dissecadas em faixas metamórficas e as Cimeiras Tabulares nos arenitos da Formação Serra dos Martins e estão dentro do conjunto regional do Planalto da Borborema) e a Depressão Intraplanáltica do rio Carnaúba, sendo esta última dividida em pedimentos dissecados e pedimentos retocados amplos, onde se encontram os sedimentos quaternários do rio Carnaúba, compondo um setor do conjunto regional Depressão Sertaneja.

Os sítios arqueológicos estão distribuídos nesses dois grandes compartimentos, ora nas encostas dissecadas que bordejam as cimeiras, ora nos pedimentos nos setores intraplanálticos do rio principal, $\mathrm{o}$ Carnaúba. Dentro do contexto arqueológico da bacia, também se faz um destaque a um tributário importante da Carnaúba, o Riacho Olho D'água/Bojo. O destaque se justifica pela presença densa de sítios arqueológicos ao longo do seu eixo, seja sítios a céu aberto, paredões, ou abrigos sob rocha. Foram realizados também alguns gráficos para quantificar os sítios quanto ao seu tipo (Gráfico 1), assim como a quantidade de sítios distribuídos em função do seu tipo e a unidade geomorfológica correspondente (Gráfico 2), e, diante disso, a discussão foi conduzida a partir da distribuição dos tipos de sítios arqueológicos em face da sua posição geomorfológica na bacia do rio Carnaúba. 
Gráfico 1. Relação do total de sítios arqueológicos e seus tipos

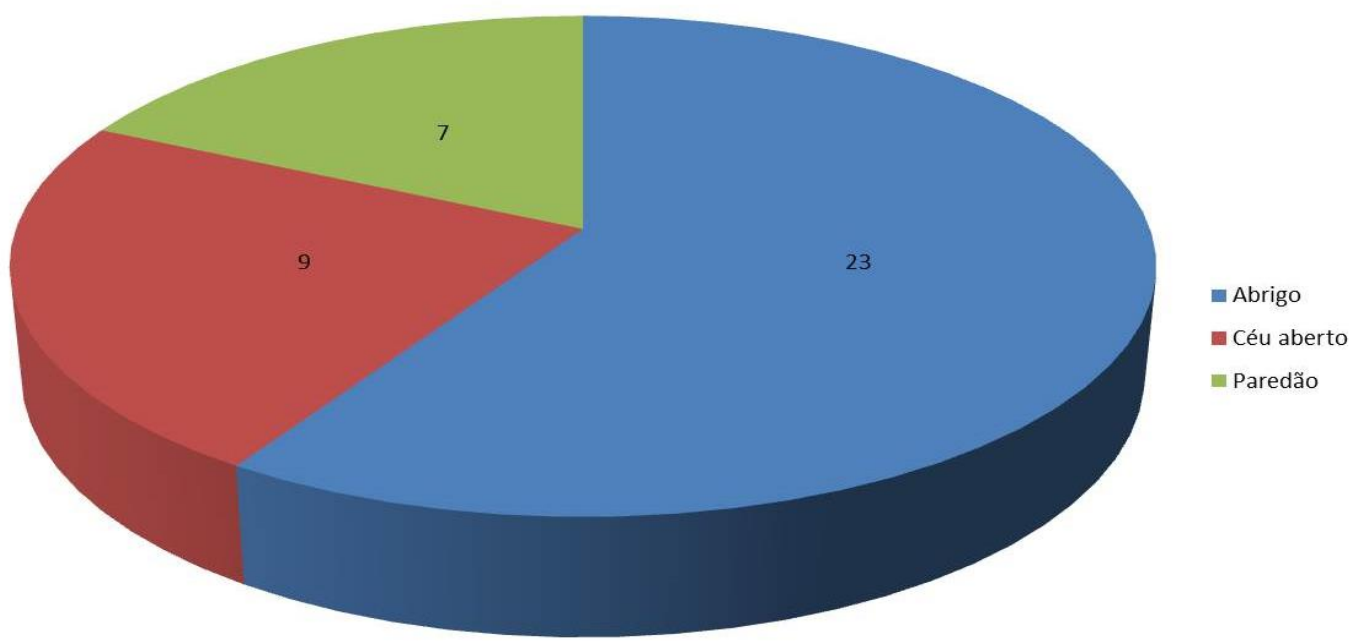

Org. Autores (2020)

Gráfico 2. Relação de unidades geomorfológicas e tipos de sítios

\section{Unidades Geomorfológicas e Tipos de Sítios}

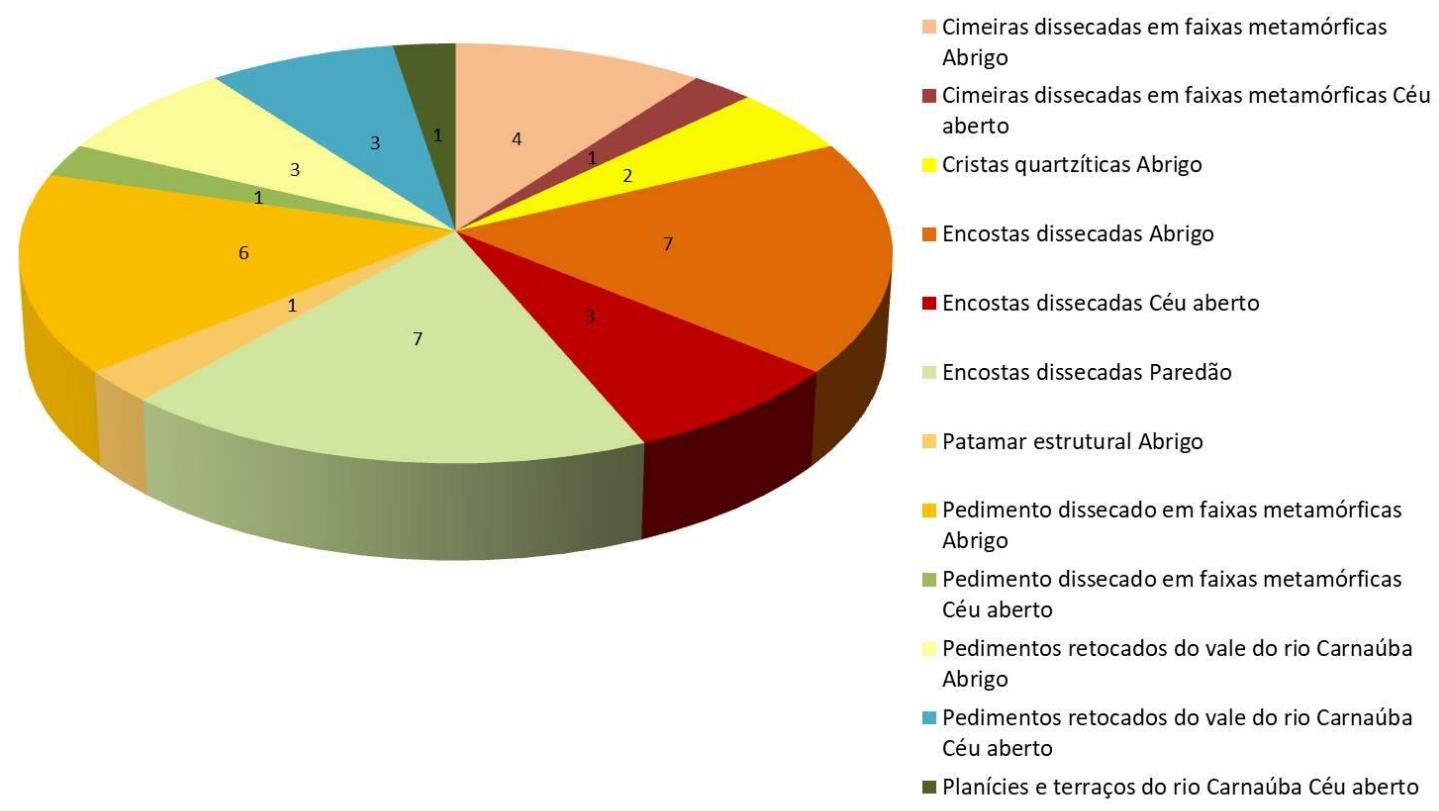

Org. Autores (2020)

Através da interpretação dos dados de contagem e caracterização e a representação destes no mapa hipsométrico e de declividade (Figuras 2 e 3), foi possível observar um padrão entre as posições na paisagem física, as unidades geomorfológicas, e os quatro tipos observados de sítio 
MEDEIROS, B. A.; TAVARES, B. A. C.; MÜTZENBERG
ANÁLISE DA DISTRIBUIÇÃO ESPACIAL DOS SÍTIOS ARQUEOLÓGICOS DA BACIA

DO RIO CARNAUUBA-RN A PARTIR DA CLASSIFICACCAOO DA MORFOLOGIA DOS SUPORTES ROCHOSOS E DAS UNIDADES GEOMORFOLÓGICAS

de acordo com a sua morfologia: i) Abrigo; (ii) Céu aberto; e (iii) Paredão (Figura 5), por consequente, também dos seus registros (Tabela 1).

Figura 5. Modelos da classificação com base morfológica dos sítios arqueológicos. A - Abrigo sob rocha, B - Paredão, C.1 - Céu aberto em contexto dos pedimentos e terraços fluviais. C. 2 -

Céu Aberto em contexto de lajedo (afloramento rochoso)
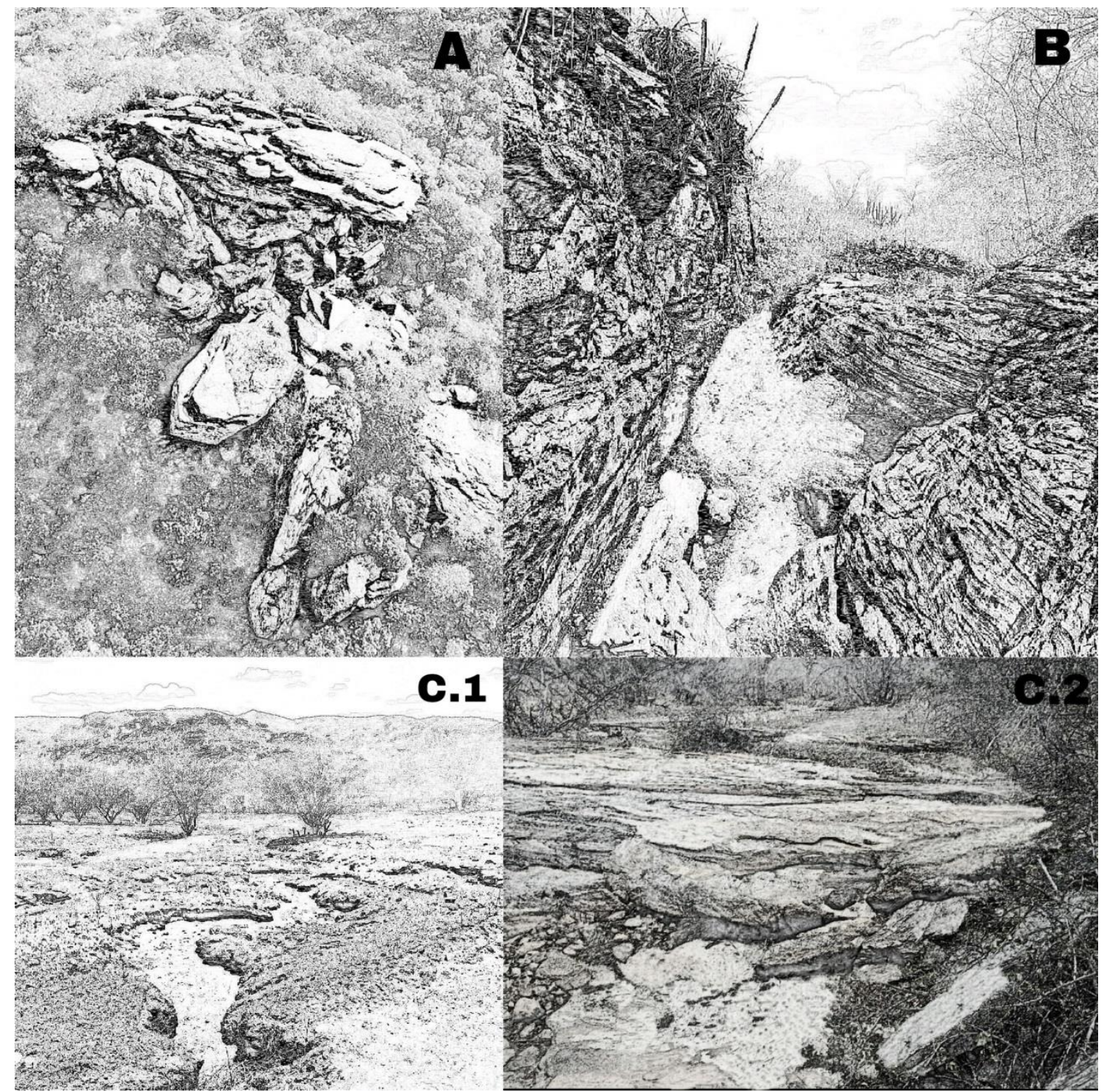

Tabela 1. Relação das unidades geomorfológicas, tipo de sítio arqueológico e os valores encontrados

\begin{tabular}{lr} 
Rótulos de Linha & Contagem de nome \\
\hline Cimeiras dissecadas em faixas metamórficas & $\mathbf{5}$ \\
\hline Abrigo & 4 \\
Céu aberto & 1 \\
Cristas quartzíticas & $\mathbf{2}$
\end{tabular}


Abrigo 2

Encostas dissecadas 17

$\begin{array}{ll}\text { Abrigo } & 7\end{array}$

Céu aberto 3

Paredão 7

Patamar estrutural 1

Abrigo 1

Pedimento dissecado em faixas metamórficas $\quad 7$

Abrigo 6

Céu aberto 1

Pedimentos retocados do vale do rio Carnaúba 6

Abrigo 3

Céu aberto 3

Planícies e terraços do rio Carnaúba $\quad 1$

Céu aberto 1

Total Geral 39

Fonte: Autores

A partir disso, foram, então, estabelecidas as seguintes considerações

1) 24 sítios do tipo abrigo estão distribuídos em áreas entre 312 e 560 metros, a maior variabilidade observada, apontando para uma maioria localizada nos setores mais elevados da Bacia do Rio Carnaúba, onde estão compartimentos Cimeiras em faixas metamórficas, e possuem registros predominantemente de pinturas rupestres, com poucos casos de gravuras. Em alguns casos existe sedimentação, o que permitiu conservar vestígios de ocupações e enterramentos, como no caso específico do sítio Pedra do Alexandre. Apesar dos sítios do tipo abrigo estarem bem distribuídos em todas as unidades geomorfológicas, há uma predominância destes nas Encostas Dissecadas. Essa predominância está relacionada à influência da formação dos abrigos em encosta negativa. Estas feições podem ser originadas a partir dos processos de intemperismo que ocorrem diretamente nos contatos das rochas metamórficas por erosão diferencial. Os abrigos também tem sua evolução vinculada a diferenças estruturais a partir de fraturas e falhas e contatos litológicos pela presença de stocks.

2) 9 sítios do tipo céu aberto estão distribuídos em áreas entre 320 e 572 metros, dispostos majoritariamente nos terraços do canal principal do rio Carnaúba e seus tributários, estando localizados geomorfologicamente no compartimento morfoestrutural Depressão Sertaneja, localmente denominado de Depressão Intraplanáltica do rio Carnaúba. Esta morfoestrutura abrange as unidades das planícies e terraços aluviais e os pedimentos retocados, este último onde estão 4 destes sítios. Apesar da diferenciação hipsométrica, os sítios obedecem a um padrão em relação a sua distribuição e estão mais próximos dos níveis de base local da bacia, onde está disposta a grande concentração de sedimentação quaternária, que dá suporte a esse tipo de sítio. Possuem registros predominantemente de artefatos líticos, como os sítios Lajedo e Riacho das Relíquias, e alguns casos com presença de estruturas de combustão, como no sítio Galo. Além destes, ainda existe o sítio Lajedo do Dean, que contém gravuras rupestres. Dentre a categoria de Céu aberto há alguns sítios que estão vinculados aos vales fechado em gargalo, próximos aos rios ou até mesmo no leito do rio, apresentam características específicas de lajedos, com a rocha exposta. Estes sítios possuem registros predominantemente de gravuras rupestres, apenas um caso com pintura. A concentração desses últimos em áreas de dissecação (Cristas dissecadas em faixas metamórficas, Encostas dissecadas e o setor do Vale Suspenso), e 
MEDEIROS, B. A.; TAVARES, B. A. C.; MÜTZENBERG
ANÁLISE DA DISTRIBUIÇÃO ESPACIAL DOS SÍTIOS ARQUEOLÓGICOS DA BACIA

DO RIO CARNAÚBA-RN A PARTIR DA CLASSIFICACCAOO DA MORFOLOGIA DOS SUPORTES ROCHOSOS E DAS UNIDADES GEOMORFOLÓGICAS

aos canais confinados que compõem a bacia, principalmente o vale do Riacho Olho D’água/Bojo onde está a maior concentração de sítios com gravura da chamada Tradição Itaquatiara;

3) 7 sítios do tipo paredão estão distribuídos em áreas entre 379 e 477 metros, estritamente próximos ao curso do rio, bem distribuídos em áreas de encostas dissecadas, e possuem registros predominantemente de gravura, com variações para pintura, sítios como o Cachoeira do Canoas no riacho do Bojo/Olho D'água, e o complexo dos Fundões I, II e III. A Geomorfologia é bem característica de um controle da dissecação formando vales em gargalo e riachos controlados estruturalmente a partir de contatos litológicos da Formação Equador e Seridó e stocks estruturais condicionando a disposição das encostas que confinam os riachos e consequentemente são as feições utilizadas como painel para a prática dos grafismos rupestres (Figura 6, 7 e 8).

Figura 6. A: Encostas dissecadas e pedimentos retocados amplos. Destaque para o setor central onde se alojam a sedimentação quaternária proveniente da dinâmica fluvial do rio Carnaúba. B: Cristas quartzíticas em primeiro plano e os setores de Cimeira Tabulares na Formação Serra dos Martins ao Fundo.

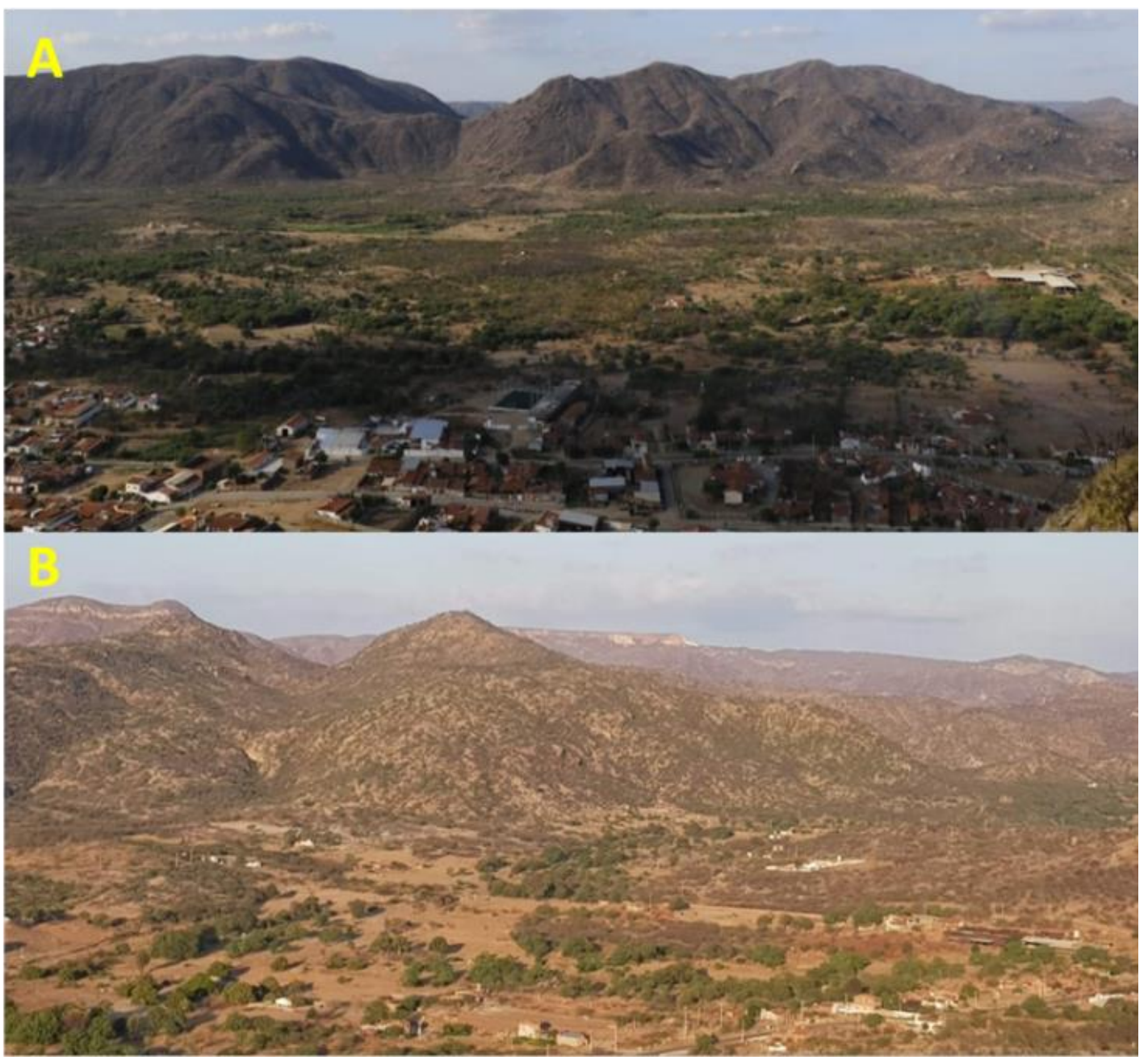

Org. Autores (2020) 
MEDEIROS, B. A.; TAVARES, B. A. C.; MÜTZENBERG
ANÁLISE DA DISTRIBUIÇÃO ESPACIAL DOS SÍTIOS ARQUEOLÓGICOS DA BACIA

DO RIO CARNAÚBA-RN A PARTIR DA CLASSIFICACÃO DA MORFOLOGIA DOS SUPORTES ROCHOSOS E DAS UNIDADES GEOMORFOLÓGICAS

Figura 7. A e B - Pedimentos retocados em rochas metamórficas. C - Encostas Dissecadas. D Pedimentos dissecados em faixas metamórficas e Cristas Quartzíticas ao fundo. E - Abrigo em encosta negativa do sítio arqueológico Pedra do Alexandre nos setores de pedimentos dissecados em faixas metamórficas. $\mathrm{F}$ - Vale do rio Carnaúba no setor dos pedimentos dissecados e Cristas Quartzíticas ao fundo marcado os setores elevados marcando a porção central da bacia.

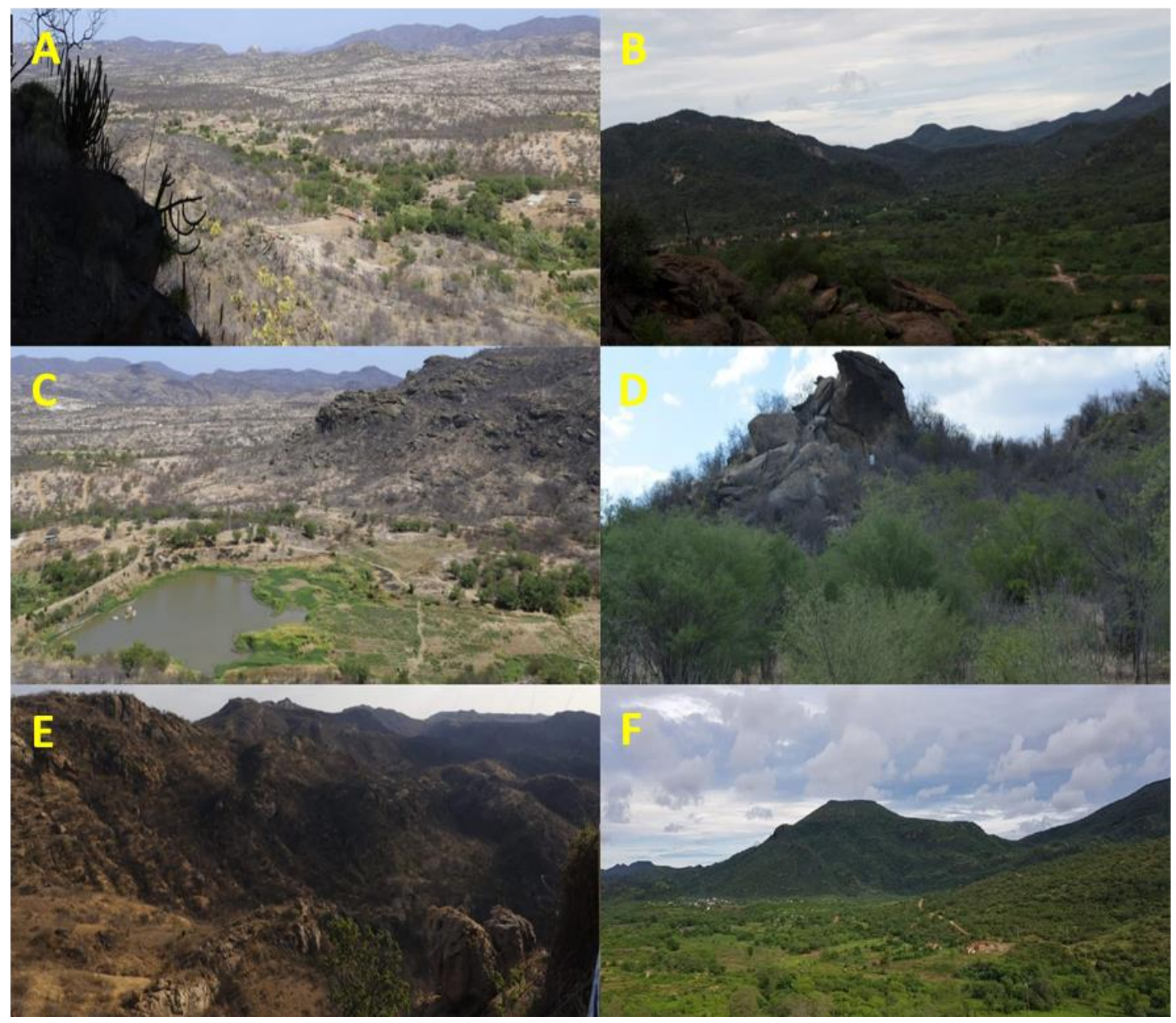

Org. Autores (2020)

\section{CONSIDERAÇÕES FINAIS}

Portanto, analisando os resultados obtidos, percebe-se que, além da padronização do posicionamento dos sítios em relação à paisagem anteriormente discutida, o posicionamento destes no eixo principal do rio Carnaúba é retrato direto da geomorfologia. No que diz respeito aos sítios de abrigo sob rocha, observa-se que estão majoritariamente posicionados em setores de encosta (estes sendo resultado da erosão diferencial entre os tipos e estrutura das rochas, o que permitiu suas formações em geral sob encosta negativa), e voltam-se para o eixo principal do rio, fato que demonstra uma escolha preferencial de locais próximos ao vale, tanto para o acesso à recursos naturais, quanto para obtenção de matéria-prima. Já nos sítios a céu aberto, percebe-se uma tendência a estarem próximos à terraços fluviais, ao nível de base local e aos pedimentos dissecados, localizados na Depressão Intraplanáltica do rio, estes sítios também estão associados aos ambientes fluviais stricto sensu, sob a disposição de lajedos ao longo dos 
MEDEIROS, B. A.; TAVARES, B. A. C.; MÜTZENBERG
ANÁLISE DA DISTRIBUIÇÃO ESPACIAL DOS SÍTIOS ARQUEOLÓGICOS DA BACIA

DO RIO CARNAÚBA-RN A PARTIR DA CLASSIFICACÃO DA MORFOLOGIA DOS

SUPORTES ROCHOSOS E DAS UNIDADES GEOMORFOLÓGICAS

eixos de drenagem tributários ao rio Carnaúba, sendo estes característicos pela presença dos registros com a técnica da gravura. Por fim, nota-se nos sítios dos tipos Paredão a vinculação aos leitos rochosos dos rios, principalmente no setor de um dos seus principais tributários, o Olho D'água/Riacho do Bojo, onde o leito é essencialmente confinado, e as encostas verticais atuaram como suporte para a prática dos grafismos.

Dessa forma, conclui-se a presente pesquisa reforçando a importância de estudos e discussões na área da Geoarqueologia com enfoque na disposição dos sítios em face da geomorfologia. Assim, foi possível verificar que a bacia do rio Carnaúba apresentou uma concentração de sítios sob a forma de abrigos nos setores de encostas dissecadas. Os abrigos estarem em consonância a essa unidade geomorfológica, demonstra que a geomorfologia da bacia do rio Carnaúba, possibilitou a formação desses espaços de ocupação voltados para os vales amplos do rio Carnaúba ou os vales confinados dos seus principais afluentes, em ambos os casos, os setores de encostas sugerem uma predileção na escolha desses ambientes. Essa condição pode reforçar o papel que a disposição da drenagem também pode ter atuado como um condutor da disposição das ocupações pré-históricas no vale.

\section{REFERÊNCIAS}

BUTZER, K. Archaeology as Human Ecology: Method and Theory for a Contextual Approach. Cambridge: Cambridge University Press, 1982.

CHAGAS JÚNIOR, J.C. Arqueologia espacial no Seridó potiguar: análise e interpretação arqueológica do território na bacia hidrográfica do rio Carnaúba. Recife: Dissertação (Mestrado em Arqueologia) - UFPE, 2017.

COSTA, T.C.C. et al. Análise da degradação da caatinga no núcleo de desertificação do Seridó (RN/PB). Campina Grande: Revista Brasileira de Engenharia Agrícola e Ambiental, v. 13, p. 961-974, 2009.

DANTAS, J.A. Indícios de uma civilização antiqüíssima. Fundação Casa de José Américo, 1994.

DEMEK, J.; EMBLETON, C. Guide to medium-scale geomorphological mapping. Stuttgart: International Geographical Union, Commission on Geomorphological Survey and Mapping, (1978).

GUIDON, N. Peintures rupestres de Varzea Grande, Piaui, Brazil. Paris: Cahiers d'Archaeologie d'Amerique du Sud, Vol. 3, 1975.

LEITE, M.N. A subtradição Seridó de pintura rupestre - RN: um estudo da identidade humana. Recife: Dissertação (Mestrado em Arqueologia) - UFPE, 2004.

MACEDO, H. Pesquisas arqueológicas realizadas em Carnaúba dos Dantas, Sertão do Seridó: Um balanço. Rio Grande do Norte: Anais XVII Semana de Humanidades, 2009.

MARTIN, G. O estilo "Seridó" na arte rupestre do Rio Grande do Norte. Belo Horizonte: Arquivos do Museu de História Natural, Belo Horizonte, v. 6-7, p. 379-382, 1982.

MARTIN, G. A Subtradição Seridó de pintura rupestre pré-histórica do Brasil. Recife: Clio: Série Arqueológica. Recife, n. 5, p. 19-26, 1989.

MARTIN, G. Os rituais funerários na pré-história do Nordeste. Recife: Clio: Série Arqueológica, v. 1, n. 10, p. 30-46, 1994.

MARTIN, G. Os sítios rupestres do Seridó, no Rio Grande do Norte (Brasil), no contexto do povoamento da América do Sul. Recife: Clio: Série Arqueológica, v. 1, n. 11, p. 43-57, 1996.

MARTIN, G. Fronteiras Estilísticas e Culturais na Arte Rupestre da Área. Arqueológica do Seridó (RN, PB). Recife: Clio: Série Arqueológica, v. 1, n. 16, p.11-32, 2003.

MARTIN, G. Pré-História do Nordeste do Brasil. Recife: Editora Universitária. 5.ed. 434p, 2013. 
MEDEIROS, B. A.; TAVARES, B. A. C.; MÜTZENBERG
ANÁLISE DA DISTRIBUIÇÃO ESPACIAL DOS SÍTIOS ARQUEOLÓGICOS DA BACIA

DO RIO CARNAÚBA-RN A PARTIR DA CLASSIFICAC̃̃O DA MORFOLOGIA DOS

SUPORTES ROCHOSOS E DAS UNIDADES GEOMORFOLÓGICAS

MUTZENBERG, D. Gênese e ocupação pré-histórica do Sítio Arqueológico Pedra do Alexandre: uma abordagem a partir da caracterização paleoambiental do vale do Rio Carnaúba - RN. Recife: Dissertação (Mestrado em Arqueologia) - UFPE, 2007.

MUTZENBERG, D. et al. A influência dos controles estruturais sobre a morfogênese e a sedimentação neógena na bacia do rio Carnaúba $(\mathrm{RN})$ e sua aplicação aos estudos geoarqueológicos do Seridó. Recife: Clio: Série Arqueológica, v. 19, n. 2, p. 112-125, 2005.

NOGUEIRA, M. Ocupações pré-históricas a céu aberto no vale do rio da Cobra - Carnaúba dos Dantas e Parelhas - RN. Recife: Tese (Doutorado em Arqueologia) - UFPE, 2017.

NOGUEIRA, M.; MAFRA, F. Levantamento de sítios arqueológicos a céu aberto na área arqueológica do Seridó - Rio Grande do Norte - Brasil. Caicó: Mneme: Revista de Humanidades, v. 15, n. 35, p. 244-259, 2014.

NOGUEIRA, N. As representações rupestres dos adornos de cabeça nos antropomorfos na área arqueológica do Seridó - RN. Recife: Dissertação (Mestrado em Arqueologia) - UFPE, 2016.

NUNES, B. E. et al. Manual Técnico de Geomorfologia. Rio de Janeiro: IBGE. Manuais técnicos em Geociências n.5, 2a Ed, 2009.

SALDANHA, S.M.R. Riacho das Relíquias: contribuição aos estudos de sítios a céu aberto em Carnaúba dos Dantas - RN, Brasil. Recife: Dissertação (Mestrado em Arqueologia) - UFPE, 2014.

SANTOS, H.G. et al. Sistema Brasileiro de Classificação dos Solos. Brasília: Embrapa, 5. ed. rev. e ampl, 2018.

SILVA, A.C. As representações zoomórficas na subtradição Seridó. Recife: Dissertação (Mestrado em Arqueologia) - UFPE, 2003.

SOLARI, A et al. Estudos de antropologia dental na população do sítio arqueológico Pedra do Alexandre, Carnaúba dos Dantas, RN (9.000-2.000 AP). Recife: Clio: Série Arqueológica, v. 31, n.2, p. 14-57, 2016.

VALLE, R.B.M. Gravuras pré-históricas da Área Arqueológica do Seridó Potiguar/Paraibano: um estudo técnico e cenográfico. Recife: Dissertação (Mestrado em Arqueologia) - UFPE, 2003.

VIDAL, I.A. Las representaciones hitifálicas en las pinturas rupestres de la tradición Nordeste, subtradición Seridó, Rio Grande do Norte, Brasil. Recife: Clio: Série Arqueológica, n.11, p. 141-151, 1995. 